\title{
Exploratory study on characteristics of oyster shell and eggshell quality in Chile
}

\author{
Carolina Arenas, Marcelo Hidalgo, Héctor Hidalgo, Carolina Valenzuela*
}

\begin{abstract}
This study aimed to characterise oyster shell and white egg shell quality in Chile. The work was based on samples of both oyster shell and eggs, which were sourced from 7 laying farms over a period of several weeks during the production stage. Oyster shells were characterised according to their calcium content and granulometric distribution, and were classified in three types of particles $(\mathrm{mm})$ : coarse $(\geq 1.7)$, medium-sized $(0.9-1.6)$ and fine $(\leq 0.8)$. Eggs were characterised, according to hen age and farm, by determining their weight, eggshell resistance, and thickness. Currently, Chilean farms use oyster shells whose calcium content ranges from $32.5 \%$ to $34.8 \%$, and their granulometric distribution is $51.7 \%$ coarse, $27.6 \%$ medium-sized and $18.1 \%$ fine particles. Thus, the predominant form of oyster shell traded by major companies in Chile is the coarse type of particles, followed by medium-sized and fine particles. Similar calcium contents were observed for oyster shell samples sourced from different farms. Similar weight of the eggs were found for all farms (60-64 g). Contrarily, farms presented different results for eggshell resistance (3,934-5,057 g) and eggshell thickness $(0.322-0.376 \mathrm{~mm})$. Eggshell resistance and thickness values were within the expected range for white hen eggs.

Key words: calcium, eggs, granulometry, oyster shell.
\end{abstract}

\section{INTRODUCTION}

Calcium carbonate, in the form of calcite (polymorph of calcium carbonate), is the major component of hen eggshells (Nys et al 1999), reaching levels close to $94-95 \%$ of the eggshell (Nys and Gautron 2007, Saunders-Blades et al 2009). Eggshell is a natural porous bioceramic, which is composed of a two-layered membrane and calcified extracellular matrix. Its components are sequentially assembled over 22 hours while the egg moves along the oviduct (Arias et al 1993, Arias and Fernandez 2003). The biomineralisation of eggshells has been divided into three stages: (1) the initial stage, that begins when the first crystals of calcium carbonate are deposited on mammillary knobs; (2) the growth phase, which is characterised by a rapid mineralization of the compact shell (palisade layer); and (3) the terminal phase, when the shell calcification stops along with the deposition of the cuticle (Nys and Gautron, 2007). Importantly, the mineralization process is inhibited by the eggshell membranes and the presence of collagen X that facilitates this inhibition (Arias et al 1997).

Overall, one egg can contain an average of 2.3 to 3 $\mathrm{g}$ of calcium (Nys et al 1999, Hunton, 2005). Therefore, farmers must ensure that hens receive enough calcium in their diets, closely following technical recommendations that are tailored to their specific breed, otherwise the hens will present an irregular pattern of egg laying, which may also be accompanied by smaller egg size and/or eggshell quality defects that render these eggs into products not suitable for trade (Williams 2005).

Accepted: 07.06.2018.

Facultad de Ciencias Veterinarias y Pecuarias, Universidad de Chile, Santiago, Chile.

*Corresponding author: C Valenzuela; Santa Rosa 11735, La Pintana, Santiago, Chile; cvalenzuelav@u.uchile.cl
Several sources of calcium are available for hen diets. Among them, the most important sources are limestone and oyster shell (Roland 1986, Guinotte and Nys 1991, Pizzolante et al 2011, Çatll et al 2012), and some authors consider oyster shell to have a greater bioavailability than limestone (Brister et al 1981, Saunders-Blades et al 2009). Oyster shell is widely preferred for the nutrition of laying hens in Chile, as well as in other countries, and is regarded as an excellent source of calcium (Roland and Bryant 1999, Saunders-Blades et al 2009, Pizzolante et al 2011). Oyster shell is a sedimentary rock with varying degrees of compaction, and it is mostly composed of calcareous shells remains from marine organisms, with different proportions of clastic materials (Çatli et al 2012). In Chile, this mineral is mined in the Atacama and Coquimbo regions.

One of the most important parameters that relate to eggshell quality is the absorption of dietary calcium, which is determined by the particle size of the calcium source (Guinotte and Nys 1991, Nys et al 1999). Regarding whether using a high proportion of coarse particles of oyster shell or limestone to improve eggshell quality, a revision of the current literature shows controversial information. On one hand, Koutoulis et al (2009), Çatli et al (2012), Guo and Kim (2012), and Świątkiewicz et al (2015) have shown that eggshell thickness and resistance would improve with some levels of coarse calcium granulometry in the diet. On the other hand, other authors have not found such relationship in their work (Pelicia et al 2009, Tunç and Cufadar 2015). Nonetheless, catalogues from commercial breeds provide recommendations on what particle sizes feed to hens at each stage of their development (Saunders-Blades et al 2009, ISA 2010², Hy-line 20161, Lohmann 20161).

\footnotetext{
Hy-Line. Commercial Laying Guide Hy-line Brown. http://www. hyline.com/userdocs/pages/BRN_COM_SPN.pdf ; Isa Bovans White. Commercial Layer Nutrition Management Guide. https://
} 
Currently, we are not aware of any study concerning granulometry and the proportion of oyster shell being used by laying hen-farmers in Chile. Additionally, no local information is available in Chile regarding egg weight and some eggshell quality parameters that are crucial to analyse the national situation. Considering the information presented above, this work aimed at characterising oyster shell and white eggshell quality in Chile.

\section{MATERIAL AND METHODS}

\section{OYSTER SHELL SAMPLES}

The same person selected samples of white eggs (detailed in the following section of eggshell quality) and oyster shell (500 g in quadruplicate), randomly, for each sampling time. The samples were sourced from 7 farms that are representative of $70 \%$ of Chilean laying farms (companies associated with the "Asociación de Huevos de Chile"2). Each farm was assigned a single letter code (groups A - G) to conceal their identity. Farm 'A' used two types of oyster shell products, which were assigned to codes ' 1 ' and ' 2 '. Digital photographs were captured to record the particle size of different oyster shell samples.

To determine the granulometry of oyster shells, each samples was quivered for 10 minutes in a sieve shaker (Gilson ${ }^{\circledR}$, RO-TAP, USA), passing through 13 sieves of the following opening diameters: $3.350,1.700,1.180,1.000$, $0.850,0.600,0.500,0.425,0.300,0.212,0.180,0.150$ and $0.106 \mathrm{~mm}$. No scale has been agreed to classify the size of oyster shell particles between different authors (table 1). Therefore, three particle size categories were established in this work. Coarse particles were those measuring $\geq 1.7$ $\mathrm{mm}$, medium-sized were those measuring from 0.9 to 1.6 $\mathrm{mm}$, and fine particles measured $\leq 0.8 \mathrm{~mm}$. After processing all samples and assigning them to their respective category, their relative importance was expressed as percentages.

Calcium content for each sample was determined by Inductively Coupled Plasma Optical Emission Spectrometry (ICP-OES) techniques, using an Optima 8300 spectrometer manufactured by Perkin Elmer (USA).

\section{EGGSHELL QUALITY}

Fifteen white eggs of laying hens were sampled at 10 different ages $(20,30,40,50,60,70,80,90,100$ y 110 weeks of age), and hen groups were analysed over time in each farm. Sampled farms were those that also provided oyster shell samples.

www.isapoultry.com/ /media/Files/ISA/Different\%20languages/ Spanish/ProductsCS/ISA/Guia\%20de\%20manejo\%20de\%20la\%20 nutricion\%20ISA\%20white.pdf ; Lohmann Tierzucht. Cage system guide. http://ibertec.es/docs/productos/lbcbrown.pdf

2 https://www.chilehuevos.cl/industria/asohuevo/asociados.html
Table 1. Granulometry for oyster shell particles by author and laying hen management guidelines.

\begin{tabular}{lcc}
\hline Author & Fine (mm) & Coarse (mm) \\
\hline Saunders-Blades et al (2009) & & $>4$ \\
Hunton (2005) & $<2$ & $2-5$ \\
Pizzolante et al (2011) & $<0.5$ & $>2$ \\
Tunç and Cufadar (2015) & $<2$ & $2-5$ \\
Hy-Line (2016)* & $0-2$ & $2-4$ \\
ISA (2010)* & $<2$ & $2-4$ \\
Lohmann (2016)* $^{*}$ & $0-0.5$ & $1.5-3.5$ \\
\hline
\end{tabular}

*Hy-Line. Commercial Laying Guide Hy-line Brown. http://www.hyline. com/userdocs/pages/BRN_COM_SPN.pdf

Isa Bovans White. Commercial Layer Nutrition Management Guide. https://www.isapoultry.com/ /media/Files/ISA/Different\%20languages/ Spanish/ProductsCS/ISA/Guia\%20de\%20manejo\%20de\%201a\%20 nutricion\%20ISA\%20white.pdf

Lohmann Tierzucht. Cage system guide. http://ibertec.es/docs/productos/ lbcbrown.pdf

Every egg was weighed in and then the resistance of their eggshells was measured in an Egg Force Reader device (Orka Food Technology, Israel). Eggshell thickness was measured according to the method proposed by Çatlı et al (2012), and Guo and Kim (2012). In essence, this method involves manually removing the eggshell internal membranes, and measuring the shell thickness with a caliper at both its equator and its poles. An average was calculated then based on this three measurements.

In order to compare egg weight, eggshell resistance, and eggshell thickness between farms, all measurements were averaged for each sampling time, regardless of hen age (table 4).

\section{STATISTICAL ANALYSIS}

Data analysis for granulometric distribution, calcium content, egg weight, eggshell resistance, and eggshell thickness revealed a normal distribution (Shapiro-Wilk, $P>0.05$ ). Additionally, data was subject to a one-way ANOVA and a Tukey test. The $\alpha$ level used for determination of significance was 0.05 .

Also, data was analysed calculating coefficient of determination $\left(\mathrm{R}^{2}\right)$, and Pearson's correlation coefficients ( $\mathrm{r}$ ). This allowed to establish relations between bird age and egg weight, eggshell resistance, and eggshell thickness. The $\alpha$ level used for determination of significance was 0.05 . All these data was analysed by the Infostat ${ }^{\circledR}$ version 2016 software package.

\section{RESULTS AND DISCUSSION}

\section{OYSTER SHELL CHARACTERISTICS}

Different types of oyster shell and their appearances are presented on figure 1. Flat and long flakes are typical 
from oyster shell, with its irregular edges and white yellowish-greyish shades on its surface. Their particle size is classified as coarse (figure 1A), medium-sized (figure 1B) and fine (figure 1C). These characteristics resemble what Saunders-Blades et al (2009) previously described for this material.

Table 2 presents the distribution of oyster shell samples according to the three granulometry categories proposed in this work. This distribution shows that $49 \%$ to $71 \%$ of oyster shell particles used in Chile for feeding laying hens, fell within the coarse category. The second most common category was medium-sized oyster shell particles and were characterised by a greater variability ( $17 \%$ to $45 \%)$, whereas the fine particles only represented $7 \%$ to $20 \%$ of samples. Therefore, major egg producing farms in Chile use, on average, oyster shell that is mostly composed of coarse particles, followed by medium-sized particles, and then by fine particles (see average in table 2). Though only few works have performed a similar analysis, Guinotte and Nys (1991) reported oyster shell samples that had a similar granulometric distribution. These researchers found that $91 \%$ of their samples had medium-sized particles that ranged between 1.18 and $4.75 \mathrm{~mm}$. Meanwhile, Saunders-Blades et al (2009) reported that $79.7 \%$ of their oyster shell samples had particle sizes between 2 and 4 $\mathrm{mm}$. However, these authors only regarded as coarse those particles greater than $4 \mathrm{~mm}$, and noted that $50.2 \%$ of oyster shell samples would qualify as coarse according to their criteria. They also highlighted how important is particle size for calcium solubility, as their findings indicated a lower solubility for those oyster shell particles that were greater than $2 \mathrm{~mm}$ in diameter. Zhang and Coon (1997), and Pelicia et al (2009) also concluded that in vitro solubility for oyster shell or limestone decreases proportionally as their particle size increases. This reduced solubility results in extended retention times within the gizzard, maximising calcium carbonate dissociation to $\mathrm{Ca}^{+}$, which is the mineral form that is absorbed at the intestinal level and, later on, used for shell synthesis (Roberts 2004). Other authors have also indicated that in vivo studies found that coarse oyster shell particles (> $2 \mathrm{~mm}$ ) improve calcium bioavailability (Guinotte and Nys 1991, Nys 1999). From
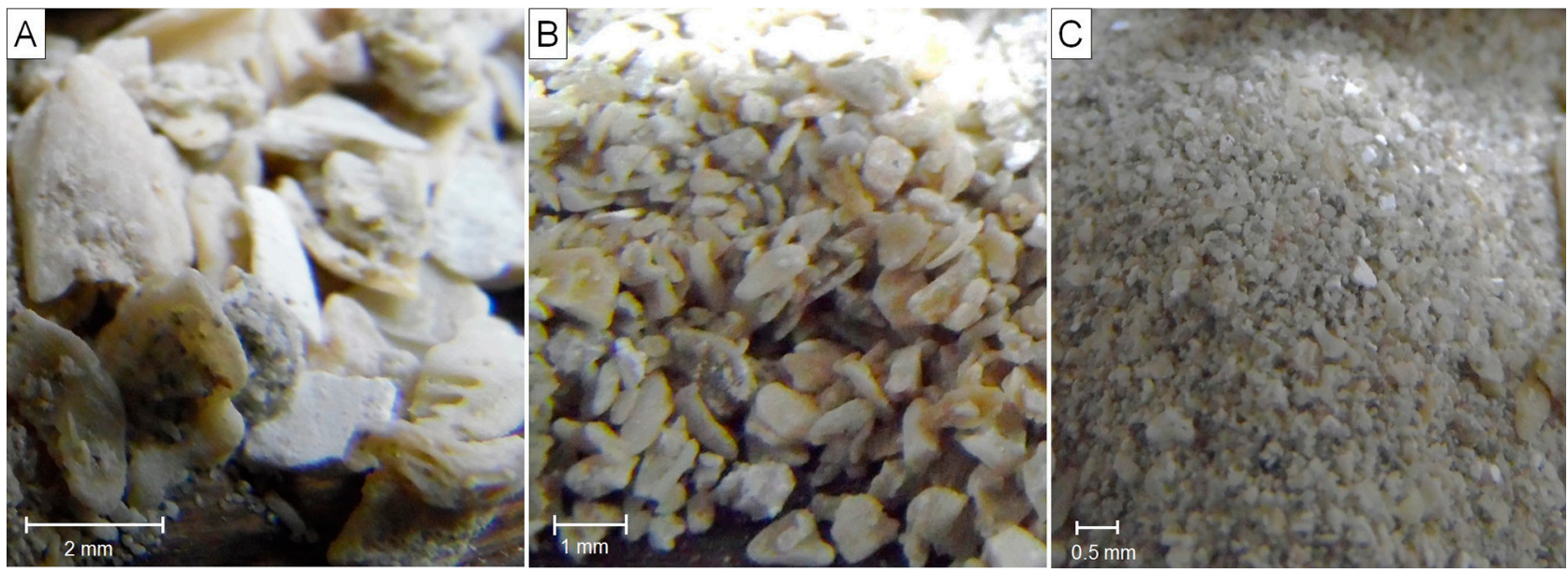

Figure. 1. Appearance for different types of particle size of oyster shell samples. A: coarse ( $\geq 1.7 \mathrm{~mm})$, B: medium-sized (1.6 a $0.9 \mathrm{~mm})$ and $\mathrm{C}$ : fine $(\leq 0.8 \mathrm{~mm})$.

Table 2. Particle size distribution and calcium content of oyster shell (average \pm standard deviation) by egg producing farms in Chile.

\begin{tabular}{lcccc}
\hline \multirow{2}{*}{ Farm } & \multicolumn{3}{c}{ Particle size } & Calcium content $(\%)$ \\
\cline { 2 - 4 } & Coarse $(\%)$ & Medium-sized $(\%)$ & Fine $(\%)$ & $33.4 \pm 0.4^{\mathrm{ab}}$ \\
\hline A-1 & $51.2 \pm 12.5^{\mathrm{a}}$ & $32.6 \pm 9.1^{\mathrm{ab}}$ & $11.4 \pm 2.4^{\mathrm{b}}$ & $32.5 \pm 0.3^{\mathrm{ab}}$ \\
A-2 & $53.5 \pm 3.4^{\mathrm{a}}$ & $31.1 \pm 3.9^{\mathrm{ab}}$ & $9.2 \pm 3.1^{\mathrm{b}}$ & $33.8 \pm 1.2^{\mathrm{a}}$ \\
B & $69.3 \pm 7.9^{\mathrm{a}}$ & $16.9 \pm 4.5^{\mathrm{b}}$ & $12.0 \pm 7.2^{\mathrm{b}}$ & $34.8 \pm 0.9^{\mathrm{a}}$ \\
C & $71.6 \pm 13.1^{\mathrm{a}}$ & $19.2 \pm 8.6^{\mathrm{b}}$ & $7.2 \pm 6.3^{\mathrm{b}}$ & $34.0 \pm 0.7^{\mathrm{a}}$ \\
D & $48.8 \pm 10.2^{\mathrm{a}}$ & $29.9 \pm 3.8^{\mathrm{ab}}$ & $19.5 \pm 7.9^{\mathrm{b}}$ & $34.5 \pm 0.9^{\mathrm{a}}$ \\
E & $54.1 \pm 9.5^{\mathrm{a}}$ & $28.8 \pm 4.5^{\mathrm{b}}$ & $16.3 \pm 6.4^{\mathrm{b}}$ & $34.8 \pm 0.6^{\mathrm{a}}$ \\
F & $56.7 \pm 8.3^{\mathrm{a}}$ & $22.7 \pm 1.7^{\mathrm{b}}$ & $18.5 \pm 7.7^{\mathrm{b}}$ & $34.2 \pm 0.7^{\mathrm{a}}$ \\
G & $56.2 \pm 10.3^{\mathrm{a}}$ & $22.4 \pm 3.1^{\mathrm{b}}$ & $19.4 \pm 9.4^{\mathrm{b}}$ & 34.0 \\
Average & 51.7 & 27.6 & 18.1 & 34.0 \\
\hline
\end{tabular}

Different letters in each column indicate significant differences $(P<0.05)$. 
this and other studies, it can be understood why breeders of commercial laying hen recommend a greater proportion of coarse particles, and state that this fraction is the most important one to provide.

Regarding calcium contents, table 2 presents values for each farm. These ranged between $33 \%$ and $35 \%$, and show small variability for samples between farms. These values were slightly lower than those reported by other authors, averaging percentages of 39.5\% (Ahmed et al 2013), 37.4\% (Çatli et al 2012), 37.5\% (Saunders-Blades et al 2009) and 36.4\% (Pizzolante et al 2011). As stated by Saunders-Blades et al (2009), oyster shell would be one calcium source that shows quite stable calcium contents, and the data above clearly supports that statement.

\section{EGG CHARACTERISTICS}

Table 3 lists egg weight, eggshell resistance, and eggshell thickness according to hen age, as well as coefficients of determination $\left(\mathrm{R}^{2}\right)$, and correlations between hen age and the variables mentioned before. Egg weight increased significantly as hen age increased. Specifically, up to $83 \%(P<0.01)$ of this weight would be determined by hen age, as shown by the highly positive association between both variables. This fact has been widely reported before in the scientific literature (Roberts 2004, Johnston and Gous 2007).

While eggshell resistance decreased as hens aged, it can be observed that on week 80 this trend was broken by the usual forced moulting that hens are put through on most farms in Chile. This resulted on more resistant eggshells, as it is expected from this practice - meant to improve both egg production and eggshell quality (AlBatshan et al 1994).

On the other hand, eggshell resistance decreased as hens aged, and eggshell thickness remained stable, though it decreased slightly on week 50 and more pronouncedly on week 110 . Up to $85 \%$ of eggshell resistance would be determined linearly by hen age, as it is evidenced by the highly negative association observed between these variables $(P=0.012)$. Similarly, table 3 shows that the data indicated that the relationship between eggshell thickness and hen age was not significant and negative $(P=0.124)$. In this regard, other studies have also reported decreasing resistance for eggshells, concluding that eggshell quality decreases along with the age of hens (Nys 1999, Silversides and Scott 2001).

It is worth noting that egg weight, eggshell resistance and thickness were found to be within the standard ranges that have been reported in the literature for white-hen eggs (Thapon and Bourgeois 1994, Roberts et al 2013). Consequently, this data might serve as a reference for egg producers in Chile, as no other studies have determined this parameters at a local level. Considering that samples in this work were sourced from farms belonging to $70 \%$ of the egg producers in the white-egg industry,
Table 3. Egg weight, eggshell resistance and thickness (average \pm standard deviation) by hen age.

\begin{tabular}{lccc}
\hline Age $($ weeks $)$ & Weight $(\mathrm{g})$ & Resistance $(\mathrm{g})$ & Thickness $(\mathrm{mm})$ \\
\hline $20(\mathrm{~N}=15)$ & $52 \pm 6^{\mathrm{a}}$ & $4,754 \pm 590^{\mathrm{a}}$ & $0.336 \pm 0.032^{\mathrm{a}}$ \\
$30(\mathrm{~N}=15)$ & $58 \pm 2^{\mathrm{b}}$ & $4,902 \pm 686^{\mathrm{a}}$ & $0.346 \pm 0.026^{\mathrm{a}}$ \\
$40(\mathrm{~N}=15)$ & $60 \pm 3^{\mathrm{b}}$ & $4,769 \pm 810^{\mathrm{a}}$ & $0.349 \pm 0.039^{\mathrm{a}}$ \\
$50(\mathrm{~N}=15)$ & $62 \pm 2^{\mathrm{b}}$ & $4,348 \pm 521^{\mathrm{b}}$ & $0.331 \pm 0.014^{\mathrm{a}}$ \\
$60(\mathrm{~N}=15)$ & $63 \pm 2^{\mathrm{b}}$ & $4,027 \pm 582^{\mathrm{b}}$ & $0.353 \pm 0.037^{\mathrm{a}}$ \\
$70(\mathrm{~N}=15)$ & $64 \pm 3^{\mathrm{b}}$ & $4,036 \pm 492^{\mathrm{b}}$ & $0.341 \pm 0.030^{\mathrm{a}}$ \\
$80(\mathrm{~N}=15)$ & $66 \pm 3^{\mathrm{c}}$ & $4,268 \pm 636^{\mathrm{b}}$ & $0.341 \pm 0.020^{\mathrm{a}}$ \\
$90(\mathrm{~N}=15)$ & $66 \pm 2^{\mathrm{c}}$ & $4,057 \pm 456^{\mathrm{b}}$ & $0.347 \pm 0.025^{\mathrm{a}}$ \\
$100(\mathrm{~N}=15)$ & $67 \pm 2^{\mathrm{c}}$ & $3,767 \pm 425^{\mathrm{c}}$ & $0.347 \pm 0.024^{\mathrm{a}}$ \\
$110(\mathrm{~N}=15)$ & $67 \pm 3^{\mathrm{c}}$ & $3,471 \pm 624^{\mathrm{c}}$ & $0.314 \pm 0.028^{\mathrm{b}}$ \\
& & Relationship & \\
Variable & Weight & Resistance & Thickness \\
Hen age & $\mathrm{R}^{2}=0.83$ & $\mathrm{R}^{2}=0.85$ & $\mathrm{R}^{2}=0.93$ \\
& $\mathrm{r}=0.91$ & $\mathrm{r}=-0.92$ & $\mathrm{r}=-0.30$ \\
$P$-value & $P=0.025$ & $P=0.012$ & $P=0.124$ \\
\hline
\end{tabular}

Different letters in each column indicate significant differences $(P<0.05)$. Coefficient of determination $\left(\mathrm{R}^{2}\right)$ and Pearson's correlation coefficient of egg weight, eggshell resistance and thickness by hen age.

Table 4. Average of egg weight, eggshell resistance and thickness (average \pm standard deviation) by farm. This calculation was made as an average of each farm, regardless of the hens age.

\begin{tabular}{lccc}
\hline Farms & Weight $(\mathrm{g})$ & Resistance $(\mathrm{g})$ & Thickness $(\mathrm{mm})$ \\
\hline A $(\mathrm{N}=150)$ & $64 \pm 5^{\mathrm{a}}$ & $4,008 \pm 271^{\mathrm{a}}$ & $0.374 \pm 0.046^{\mathrm{b}}$ \\
$\mathrm{B}(\mathrm{N}=150)$ & $62 \pm 5^{\mathrm{a}}$ & $4,808 \pm 556^{\mathrm{bc}}$ & $0.340 \pm 0.011^{\mathrm{ab}}$ \\
$\mathrm{C}(\mathrm{N}=150)$ & $63 \pm 3^{\mathrm{a}}$ & $3,954 \pm 483^{\mathrm{a}}$ & $0.331 \pm 0.008^{\mathrm{a}}$ \\
$\mathrm{D}(\mathrm{N}=150)$ & $60 \pm 5^{\mathrm{a}}$ & $5,057 \pm 623^{\mathrm{c}}$ & $0.376 \pm 0.012^{\mathrm{b}}$ \\
E $(\mathrm{N}=150)$ & $60 \pm 8^{\mathrm{a}}$ & $4,115 \pm 349^{\mathrm{ab}}$ & $0.322 \pm 0.017^{\mathrm{a}}$ \\
F $(\mathrm{N}=150)$ & $61 \pm 5^{\mathrm{a}}$ & $3,934 \pm 613^{\mathrm{a}}$ & $0.326 \pm 0.024^{\mathrm{a}}$ \\
$\mathrm{G}(\mathrm{N}=150)$ & $63 \pm 4^{\mathrm{a}}$ & $4,042 \pm 708^{\mathrm{a}}$ & $0.354 \pm 0.023^{\mathrm{ab}}$ \\
Average & 62 & 4,246 & 0.341 \\
\hline
\end{tabular}

Different letters in each column indicate significant differences $(P<0.05)$.

these data can be deemed quite representative of the national situation.

When data was analysed according to farm performance (table 4), it could be observed that farm D presented the greatest eggshell resistance values, followed by farm B. These results were unexpected, as farm D had the lowest proportion of coarse particles (table 2). In this regard, the resistance of the shell depends of multiple factors, such as: the different commercial breeds used by each farm and the age of their hens (Ketelaere et al 2002), management factors (temperature, humidity, ventilation, etc.), stress level of the hens and their sanitary status, calcium content, Vitamin D and solubility for the chosen calcium source (Roberts 2004, Pelicia et al 2009). It also depends on meat 
and bone meal or other calcium supplementation sources in the diet like bi-tri-calcium phosphates and others (Çatli et al 2012), and production system (Roberts 2004). Also important are some egg characteristics such as their microstructure (Carnarius et al 1996), morphological index (Altuntaş and Şekeroğlu 2008) and eggshell thickness uniformity (Yany et al 2014).

Farms A and D provided eggs with the greatest eggshell thickness while other farms showed similar values for this variable. Oddly enough, farms A and D had the lowest proportion of coarse particles (table 2).

The main contribution of this study was to describe the oyster shell used in Chile, which is mainly composed by coarse particles followed by medium-sized and fine particles, as suggested by the catalogues of the genetic lines of hens used in Chile. In addition, it was found that the eggs produced in Chile follow the international standards regarding eggshell quality.

\section{ACKNOWLEDGEMENTS}

The authors would like to thank Veterquímica S.A. Chile for providing financial support for the analyses.

\section{REFERENCES}

Ahmed N, Abdel K, Elamin K, Dafalla K, Malik H, et al. 2013. Effect of dietary calcium sources on laying hens performance and egg quality. J Anim Prod Adv 3, 226-231.

Al-Batshan HA, Scheideler SE, Black BL, Garlich JD, Anderson KE. 1994. Duodenal calcium uptake, femur ash, and eggshell quality decline with age and increase following molt. J Poult Sci 73, 1590-1596.

Altuntaş E, Şekeroğlu A. 2008. Effect of egg shape index on mechanical properties of chicken eggs. J Food Eng 85, 606-612.

Arias JL, Fernandez MS. 2003. Biomimetic processes through the study of mineralized shells. Mater Charact 50, 189-195.

Arias JL, Fink DJ, Xiao S, Heuer AH, Caplan AI. 1993. Biomineralization and eggshells: cell-mediated acellular compartments of mineralized extracellular matrix. Int Rev Cytol 145, 217-250.

Arias JL, Nakaruma O, Fernandez MS, Wu JJ, Knigge P, et al. 1997. Role of type X collagen on experimental mineralization of eggshell membranes. Connect Tiss Res 36, 21-31.

Brister RD, Linton SS, Creger CR. 1981. Effects of dietary calcium sources and particle size on laying hen performance. J Poult Sci $60,2648-2654$

Carnarius KM, Conrad KM, Mast MG, Macneil JH. 1996. Relationship of eggshell ultrastructure and shell strength to the soundness of shell eggs. J Poult Sci 75, 655-663.

Çatli A, Bozkurt M, Küçükyilmaz K, Çinar M, Bintas E, et al. 2012. Performance and egg quality of aged laying hens fed diets supplemented with meat and bone meal or oyster shell meal. S Afr J Anim Sci 42, 74-82.

Guinotte F, Nys Y. 1991. Effects of particle size and origin of calcium sources on eggshell quality and bone mineralization in egg laying hens. J Poult Sci 70, 583-592.
Guo X, Kim I. 2012. Impacts of limestone multi-particle size on production performance, egg shell quality, and egg quality in laying hens. Asian-Australas J Anim Sci 25, 839-844.

Hunton P. 2005. Research on eggshell structure and quality: an historical overview. Rev Bras Cienc Avic 7, 67-71.

Johnston SA, Gous RM. 2007. Modelling the changes in the proportions of the egg components during a laying cycle. Br Poult Sci 48, 347-353.

Ketelaere BD, Govaerts T, Coucke P, Dewil E, Visscher J, et al. 2002. Measuring the eggshell strength of 6 different genetic strains of laying hens: techniques and comparisons. Br Poult Sci 43, 238-244.

Koutoulis K, Kyriazakis I, Perry G, Lewis P. 2009. Effect of different calcium sources and calcium intake on shell quality and bone characteristics of laying hens at sexual maturity and end of lay. Int J Poult Sci 8, 342-348.

Nys Y. 1999. Nutritional factors affecting eggshell quality. Czech J Anim Sci 44, 135-143.

Nys Y, Hincke MT, Arias JL, Garcia-Ruiz JM, Solomon SE. 1999. Avian eggshell mineralization. Avian Poult Biol Rev 10, 143-166.

Nys Y, Gautron J. 2007. Structure and formation of the eggshell. In: Huopalahti R, López-Fandiño R, Anton M, Schade R (eds). Bioactive egg compounds. Springer, Heidelberg Berlin, Germany, Pp 99-102.

Pelicia K, Garcia E, Móri C, Faitarone A, Silva A, et al. 2009. Calcium levels and limestone particle size in the diet of commercial layers at the end of the first production cycle. Rev Bras Cienc Avic 11, 87-94.

Pizzolante C, Kakimoto S, Saldanha E, Laganá C, Souza H, et al. 2011. Limestone and oyster shell for brown layers in their second egg production cycle. Rev Bras Cienc Avic 13, 103-111.

Roberts JR. 2004. Factors affecting egg internal quality and egg shell quality in laying hens. J Poult Sci 41, 161-177.

Roberts JR, Chousalkar K, Samiullah S. 2013. Egg quality and age of laying hens: implications for product safety. Anim Prod Sci 53, 1291-1297.

Roland DA. 1986. Eggshell quality IV: oyster shell versus limestone and the importance of particle size or solubility of calcium source. Worlds Poult Sci J 42, 166-171.

Roland DA. 1999. Bryant M. Optimal shell quality possible without oyster shell. Feedstuffs 71, 18-19.

Saunders-Blades JL, Maclsaac JL, Korver DR, Anderson DM. 2009. The effect of calcium source and particle size on the production performance and bone quality of laying hens. J Poult Sci 88, 338-353.

Silversides FG, Scott TA. 2001. Effect of storage and layer age on quality of eggs from two lines of hens. J Poult Sci 80, 1240-1245.

Świątkiewicz S, Arczewska-Włosek A, Krawczyk J, Puchała M, Józefiak D. 2015. Effects on performance and eggshell quality of particle size of calcium sources in laying hens' diet with different Ca concentrations. Arch Tierz 58, 301-307.

Thapon J, Bourgeois C. 1994. The egg and the egg products. Corlet, Conde-sur-Noireau, France.

Tunç A, Cufadar Y. 2015. Effect of calcium sources and particle size on performance and eggshell quality in laying hens. Turk J Vet Anim Sci 3, 205-209.

Williams TD. 2005. Mechanisms underlying the costs of egg production. Biosci 55, 39-48.

Yany C, Lian L, Zheng J, Xu G, Yang N. 2014. Effect of uniformity of eggshell thickness on eggshell quality in chickens. J Poult Sci $51,338-342$.

Zhang B, Coon C. 1997. The relationship of calcium intake, source, size, solubility in vitro and in vivo, and gizzard limestone retention in laying hens. J Poult Sci 76, 1702-1706. 
